\title{
RETROSPECTIVE ANALYSIS OF ORTHODONTIC TREATMENT OUTCOMES AND ITS RELATION TO POSTRETENTION STABILITY*
}

\author{
ANÁLISE RETROSPECTIVA DOS RESULTADOS DOS TRATAMENTOS ORTODÔNTICOS E \\ SUA RELAÇÃO COM A ESTABILIDADE PÓS-CONTENÇÃO
}

\begin{abstract}
Karina Maria Salvatore de FREITAS ${ }^{1}$, Marcos Roberto de FREITAS², Guilherme JANSON², Arnaldo PINZAN ${ }^{3}$, José Fernando Castanha HENRIQUES ${ }^{2}$
\end{abstract}

1- DDS, MSc, Orthodontics Graduate Student. Department of Orthodontics. Bauru Dental School, University of São Paulo, Brazil.

2- DDS, MSc, PhD. Full Professor. Department of Orthodontics. Bauru Dental School, University of São Paulo, Brazil.

3- DDS, MSc, PhD. Associate Professor. Department of Orthodontics. Bauru Dental School, University of São Paulo, Brazil.

* This paper is based on research by Dr Karina Maria Salvatore de Freitas in partial fulfillment of the requirements for the Doctor degree in Orthodontics at Bauru Dental School, University of São Paulo.

Corresponding address: Dr. Karina Maria Salvatore de Freitas - Al. Octávio Pinheiro Brisolla, 9-75 - Cep 17012-901 - Bauru - SP

Tel: (14) 3235-8333 - Fax: (14) 32341961 - e-mail: kmsf@uol.com.br

Received: October 18, 2005 - Modification: April 27, 2006 - Accepted: June 20, 2006

\begin{abstract}
O

bjective: The present study was designed to retrospectively evaluate Class I malocclusion cases treated with extraction of the four first premolars, aiming to establish the relationship between the quality of orthodontic treatment outcomes and the long-term occlusal stability. Material and methods: The sample comprised 94 patients of both genders, presenting Class I malocclusion, treated with extractions of the four first premolars and Edgewise mechanics. All the patients selected were whites, being 50 males and 44 females. The mean pretreatment age was 13.46 years (s.d. 1.8). The mean treatment time was 2.09 years (s.d. 0.58), the mean retention time was 1.63 years (s.d. 0.73 ) and the mean time of postretention evaluation was 5.31 years (s.d. 1.61). The dental casts were measured at pretreatment (T1), posttreatment (T2) and postretention (T3), by the PAR index and by the Little irregularity index, and the correction due to treatment (T1-2) and the change at the postretention period (T3-2) were calculated. The descriptive statistics was performed and the Pearson correlation coefficient was applied for the PAR and the Little indices in the total sample, among the times evaluated. Results: The mean PAR reduction due to treatment was $78.54 \%$, and $66.6 \%$, at the postretention stage related to pretreatment stage. Significant correlations were found for the PAR index at the times evaluated, except between T1 and T2 and between T1-2 and T3. In other words, the higher the treatment correction (T1-2), the lower the posttreatment PAR index (PAR T2) will be, and the higher will be the PAR change at the postretention period (PAR T3-2). Also, the higher the posttreatment PAR score (PAR T2), the higher will be the postretention PAR score (PAR T3).Conclusion: It was concluded that the quality of orthodontic treatment outcomes is not related to the long-term occlusal stability.

Uniterms: Treatment outcomes; Recurrence; Orthodontics.
\end{abstract}

\begin{abstract}
RESUMO
bjetivo: O presente estudo objetivou analisar retrospectivamente casos com má oclusão de Classe I tratados com extrações dos quatro primeiros pré-molares, visando estabelecer a relação da qualidade dos resultados dos tratamentos ortodônticos e a estabilidade em longo prazo. Material e métodos: A amostra consistiu de 94 pacientes de ambos os gêneros, apresentando má oclusão de Classe I, tratados com extrações dos quatro primeiros pré-molares e mecânica Edgewise. Todos os pacientes selecionados eram leucodermas, sendo 50 do gênero masculino e 44 do feminino. A idade inicial média foi de 13.46 anos (d.p. 1.8). O tempo de tratamento médio foi 2.09 anos (d.p. 0.58), o tempo médio de contenção foi 1.63 anos (d.p. 0.73) e o tempo médio de avaliação pós-contenção, 5.31 anos (d.p.1.61). Foram medidos, nos modelos de estudo, o índice PAR e o índice de irregularidade de Little, nas fases pré (T1), pós-tratamento (T2) e pós-contenção (T3), e calculou-se a quantidade de correção com o tratamento (T1-2) e de alteração no período pós-contenção (T3-2). Realizou-se a estatística descritiva e o coeficiente de correlação de Pearson foi aplicado entre os índices estudados e os tempos avaliados. Resultados: A média de redução do índice PAR da amostra total com o tratamento foi de 78.54\%, e na fase pós-contenção, de 66.6\%, com relação ao inicial. Houve correlação significante para o índice PAR nos tempos estudados, exceto entre T1 e T2 e entre T1-2 e T3. Ou seja, quanto maior a correção do tratamento (T1-2), menor será o índice PAR final (PAR T2), e maior a alteração no período pós-contenção (PAR T3-2). E quanto maior o índice PAR pós-tratamento (PAR T2), maior o índice PAR pós-contenção (PAR T3).Conclusão: Concluiu-se que a qualidade dos resultados dos tratamentos ortodônticos não está relacionada à estabilidade oclusal em longo prazo.

Unitermos: Resultado de tratamento; Recidiva; Ortodontia.
\end{abstract}




\section{INTRODUCTION AND STATEMENT OF THE PROBLEM}

It is widely considered that some occlusal changes following orthodontic treatment are inevitable $\mathrm{e}^{27,29,38,40}$. Therefore, the possibility to be able to accurately predict the likelihood of various types of occlusal changes occurring posttreatment would be of great benefit to orthodontists. For that reason, the effects of many diagnostic and treatment factors on short and long-term occlusal stability have been broadly investigated ${ }^{8,14,15,25,26,28,39}$.

Despite of all these researches in this matter, there has still been little detailed study of the relationship between the provision of a well-detailed occlusion and long-term posttreatment stability, although such a well-detailed occlusion, with the best esthetic and occlusal results as possible, has been recommended for some time ${ }^{5,36}$. This may be related to the fact that a widely acceptable and reproducible method of occlusal assessment has not been yet available ${ }^{40}$. However, there are many systems of occlusal assessment ${ }^{9,16,32,33}$, and recently one of them has been widely promoted and used ${ }^{32}$. It is called Peer Assessment Rating (PAR) Index, and has been frequently subject of studies $3,4,6,7,11,13,19,23,29-31,40$, with great acceptance.

The present study was designed to retrospectively evaluate, by means of the use of the PAR index ${ }^{32}$ and the Little irregularity index ${ }^{24}$, Class I malocclusion cases treated with extraction of the four first premolars, aiming to establish the relationship between the quality of orthodontic treatment outcomes and the long-term occlusal stability.

\section{MATERIALAND METHODS}

\section{Material}

The sample comprised the retrospective records of 94 patients treated by postgraduate students at Bauru Dental School, University of São Paulo. Patients were chosen for the sample according to the following criteria:

- Class I malocclusion present at the beginning of orthodontic treatment;

- Treatment protocol with extraction of the four first premolars;

- Complete course of orthodontic treatment with full maxillary and mandibular fixed appliance (slot 0.022” x 0.025”), with Edgewise mechanics;

- All permanent teeth erupted until the first molars, at the pretreatment stage;

- Absence of tooth agenesis and anomalies;

- Maxillary removable (Hawley) and mandibular fixed (3x3) retainers worn for at least one year posttreatment, and no retention at the time of follow-up record;

- Pretreatment, posttreatment and postretention dental casts available at the time of the study.

All patients selected were whites of both genders, being 50 males and 44 females. The mean pretreatment age of the patients was 13.46 years (s.d. 1.8). The mean treatment time was 2.09 years (s.d. 0.58), the mean time that the retainers were used was 1.63 years (s.d. 0.73 ) and the mean time of postretention evaluation was 5.31 years (s.d. 1.61).

\section{Methods}

Pretreatment (T1), posttreatment (T2) and postretention (T3) dental casts were used. All dental cast measurements were performed with a $0.01 \mathrm{~mm}$ precision digital caliper (Mitutoyo caliper - Mitutoyo South America - model/code 500-143B) by one calibrated examiner (KMSF). The assessed variables were: Little irregularity index ${ }^{24}$ and the PAR index, as described by Richmond, et al. ${ }^{32}$ (1992), and scored with the American weight ${ }^{10}$. The degree of improvement as a result of orthodontic treatment and the posttreatment changes were assessed by two methods. The first method used the indices (PAR and Little) changes, which is the difference between the pretreatment and posttreatment scores (T1-2) and the difference between the postretention and posttreatment scores (T3-2). The second was the reduction percentage, which reflects the relative change to the pretreatment score. This is determined by the formula: T1$\mathrm{T} 2 / \mathrm{T} 1 \times 100 \%$ or $\mathrm{T} 1-\mathrm{T} 3 / \mathrm{T} 1 \times 100 \%$, where $\mathrm{T} 1$ is the pretreatment score, $\mathrm{T} 2$ is the posttreatment score and $\mathrm{T} 3$ is the postretention score.

\section{Error study}

After a one-month interval from the first measurement, the dental casts of 25 patients (75 pairs of dental casts) were randomly selected and re-measured by the same examiner (KMSF). The casual error was calculated according to Dahlberg's formula $\left(\mathrm{Se}^{2}=\Sigma \mathrm{d}^{2} / 2 \mathrm{n}\right)$ where $\mathrm{S}^{2}$ is the error variance and $d$ is the difference between the two determinations of the same variable, and the systematic error with dependent $t$ tests, for $\mathrm{p}<0.05$.

\section{Statistical analysis}

Means and standard deviations for all variables were calculated: the PAR index ${ }^{32}$ and the Little irregularity index ${ }^{24}$ at the pretreatment, posttreatment and postretention stages, the treatment change (T1-2) and the postretention change (T3-2).

Pearson's coefficient was calculated in order to verify the presence of significant correlation between the PAR scores and the Little irregularity index at all stages and phases evaluated (T1, T2, T3, T1-2 and T3-2). Results were considered significant for $\mathrm{p}<0.05$.

\section{RESULTS}

The results of the systematic and casual errors are presented in Table 1. No systematic errors were detected, and the casual errors were within acceptable levels.

Descriptive statistics of the PAR index ${ }^{32}$ and for the Little irregularity index ${ }^{24}$ at the stages and periods evaluated are shown in Table 2.

Table 3 shows the results of Pearson's correlation test, demonstrating the correlation coefficients between the variables studied and the times evaluated. 


\section{DISCUSSION}

\section{Sample}

Even though the sample evaluated in this study might appear to be small, it is still substantial considering that the patients have been evaluated more than 5 years after the end of active orthodontic treatment. It is certainly not a totally homogeneous sample because it includes patients with a wide range of treatment times and different facial patterns. However, all these patients presented the same Angle Class I malocclusion at the beginning of treatment, were treated with fixed appliances, Edgewise mechanics and the same treatment protocol, extraction of the four first premolars. These criteria of sample selection made it possible and appropriate to be used for isolation of the quality of occlusal results as a predictor or not of stability.

The fact that the patients were treated by more than one professional and by postgraduate students could create doubts in relation to the variation of the quality of final occlusion, influencing the results ${ }^{40}$. However, it has already been proven that there is no significant difference in the quality of treatment outcomes between cases treated by students and by specialists ${ }^{11}$.

It was intended to select cases with relatively similar retention times (1.63 years was the mean retention time, with a standard deviation of only 0.73 ), because it was many times mentioned in the literature that the duration of the use of retainers can affect the stability of results ${ }^{4,25,37}$. Besides, all patients had the same retention protocol, a removable Hawley in the maxillary arch and a bonded 3x3 in the mandibular arch.

\section{METHODOLOGY}

The methodology should be based on the mean objective of the study. As the purpose of this study was to correlate the quality of treatment results with the postretention stability, dental casts are the best method for evaluation of final occlusion. In spite of not allowing clinical and radiographic evaluation, the dental casts, by themselves, gather the largest amount of information related to diagnosis and to orthodontic treatment ${ }^{6,17}$. Besides, a poor association has been demonstrated between the occlusal characteristics and the morphology obtained in lateral cephalograms and a better prediction of the results by occlusal indices than by cephalometrics ${ }^{22}$. In addition, many important characteristics of the occlusion, such as amount of crowding and transverse relationship of the dental arches, cannot be appraised in cephalometrics ${ }^{6,20}$.

Andrews $^{5}$ (1972) defined the six keys to normal occlusion based exclusively on data obtained in 120 dental casts, and these keys are valuable parameters for the achievement of a static ideal occlusion. In the same way, actually the occlusal indices constitute an important research method ${ }^{2,6,7,40}$. Therefore, the PAR index was used because it was especially designed to evaluate treatment changes and outcome $e^{2,7,11}$. It has been proven valid and reliable in this assessment ${ }^{10,32}$. However, it is not sensitive to fine details of the occlusion ${ }^{19}$.

\section{Descriptive statistics}

The time of postretention observation (T2 to T3) is acceptable for the evaluation of stability, in spite of being only 5.31 years (s.d. 1.61) on average, since Al Yami, KuijpersJagtman and Van't Hof ${ }^{4}$ (1999) reported that about half of the total relapse occurs within the first two years posttreatment with good stability of most features at the period beyond 5 years.

The PAR index is an internationally recognized and

TABLE 2- Descriptive statistics of the variables evaluated

\begin{tabular}{llll}
\hline Variables & Mean & s.d. & N \\
\hline PAR T1 & 29.46 & 8.79 & 94 \\
PAR T2 & 6.32 & 3.48 & 94 \\
PAR T3 & 9.84 & 5.02 & 94 \\
PAR T1-2 & 23.14 & 9.51 & 94 \\
PAR T3-2 & 3.52 & 5.33 & 94 \\
Little T1 & 6.97 & 3.55 & 94 \\
Little T2 & 1.26 & 0.91 & 94 \\
Little T3 & 2.74 & 1.82 & 94 \\
Little T1-2 & 5.71 & 3.62 & 94 \\
Little T3-2 & 1.48 & 1.62 & 94 \\
\hline
\end{tabular}

TABLE 1- Casual and systematic errors between the $1^{\text {st }}$ and $2^{\text {nd }}$ measurements

\begin{tabular}{|c|c|c|c|c|c|c|c|}
\hline \multirow[t]{2}{*}{ Variables } & \multicolumn{2}{|c|}{$1^{\text {st }}$ measurement } & \multicolumn{2}{|c|}{$2^{\text {nd }}$ measurement } & \multirow[t]{2}{*}{$\mathbf{N}$} & \multirow[t]{2}{*}{ Dahlberg } & \multirow[t]{2}{*}{$\mathbf{P}$} \\
\hline & Mean & s.d. & Mean & s.d. & & & \\
\hline Little T1 & 7.03 & 3.53 & 6.79 & 3.54 & 30 & 0.406 & 0.502 \\
\hline Little T2 & 1.47 & 0.90 & 1.49 & 0.85 & 30 & 0.251 & 0.676 \\
\hline Little T3 & 2.82 & 1.61 & 2.85 & 1.61 & 30 & 0.219 & 0.536 \\
\hline PAR T1 & 27.20 & 6.52 & 26.93 & 6.50 & 30 & 1.322 & 0.347 \\
\hline PAR T2 & 6.16 & 3.30 & 6.30 & 2.97 & 30 & 1.095 & 0.572 \\
\hline PAR T3 & 10.46 & 3.76 & 10.70 & 3.74 & 30 & 1.012 & 0.281 \\
\hline
\end{tabular}


accepted index for recording occlusal features from dental casts $^{32}$ and it was designed to provide objective assessment of the success of orthodontic treatment ${ }^{11}$. However, there are admittedly some limitations. Importantly, changes in facial profile or cephalometric parameters that reflect the skeletal component of malocclusion are not considered in the quantitative evaluation ${ }^{10}$. Unfortunately, measurements of these variables by valid and reliable methods has not been achieved for many reasons, but no universally accepted methods currently exist to assess change in facial profile as an outcome measure ${ }^{10}$. Actually, the optimal feasible method for assessing the attainment of desired occlusal outcomes is by the use of occlusal indices. In this study, the mean PAR score for the total sample at treatment onset (T1) was 29.46 (s.d. 8.79), being reduced to 6.32 (s.d. 3.48) by the end of the active treatment (T2) and increased to 9.84 (s.d. 5.02) when assessed at the postretention stage (T3) (Table 2).

It has been suggested that a good standard of orthodontic treatment should result in a mean PAR reduction of $70 \%$ or more ${ }^{33}$. In the present study, the treatment reduced the malocclusions by about 79\%, indicating a high standard of treatment ${ }^{33}$. The results correspond well with other reports on orthodontic treatment with fixed appliances ${ }^{7,11,13,30,31,34,35,40}$.

The long-term result of $66.6 \%$ PAR score reduction implies a loss of about $13 \%$ of what was gained by treatment. Unchanged results at the follow-up period would probably be too ambitious. Similar studies reported postretention changes $^{4,7,29,31,40}$, and these changes are also found in untreated normals ${ }^{3,38}$.

TABLE 3- Results of Pearson's correlation coefficient between the PAR and the Little indices at all times evaluated

\begin{tabular}{lll}
\hline Variables & \multicolumn{1}{c}{$\mathbf{r}$} & $\mathbf{P}$ \\
\hline PAR T1 x PAR T2 & -0.090 & 0.384 \\
PAR T1 x PAR T3 & 0.256 & $0.012^{\star}$ \\
PAR T1 x PAR T1-2 & 0.918 & $0.000^{\star}$ \\
PAR T1 x PAR T3-2 & 0.302 & $0.003^{\star}$ \\
PAR T2 x PAR T3 & 0.261 & $0.010^{\star}$ \\
PAR T2 x PAR T1-2 & -0.429 & $0.000^{\star}$ \\
PAR T2 x PAR T3-2 & -0.404 & $0.000^{\star}$ \\
PAR T3 x PAR T1-2 & 0.150 & 0.147 \\
PAR T3 x PAR T3-2 & 0.774 & $0.000^{\star}$ \\
PAR T1-2 x PAR T3-2 & 0.423 & $0.000^{*}$ \\
PAR T1 x Little T3 & -0.050 & 0.626 \\
PAR T2 x Little T3 & 0.006 & 0.949 \\
PAR T3 x Little T3 & -0.029 & 0.779 \\
Little T1 x Little T2 & 0.053 & 0.606 \\
Little T1 x Little T3 & 0.380 & $0.000^{\star}$ \\
Little T2 x Little T3 & 0.459 & $0.000^{*}$ \\
\hline
\end{tabular}

* Statistically significant for $p<0.05$
In relation to Little irregularity index, the pretreatment mean was $6.97 \mathrm{~mm}$ (s.d. 3.55), it was corrected to $1.26 \mathrm{~mm}$ (s.d. 0.91) at the end of orthodontic treatment and showed a mean value of $2.74 \mathrm{~mm}$ (s.d. 1.82) at the postretention stage (Table 2). In other words, the orthodontic treatment provided a mean correction of $81.92 \%$ of the amount of mandibular anterior crowding, and during the postretention phase there was a loss of this correction, attaining $60.68 \%$ regarding the beginning of treatment. This postretention relapse observed for the irregularity index can be considered a relative stability, compared to other results found in the literature $\mathrm{e}^{14,15,25-28,39}$.

\section{Correlations}

The PAR index presented a significant correlation between its initial score and its score at postretention stage, treatment correction and alteration at the postretention period (PAR T1 x PAR T3; PAR T1 x PAR T1-2; PAR T1 x PAR T3-2) (Table 3). Interpreting these results, it can be said that the largest the severity of the malocclusion, the largest will be the treatment correction and the relapse of this correction, implying higher postretention PAR index values.

Regarding the final treatment results (T2), the PAR score was statistically significant and was correlated with changes occurring among phases T1-2 and T3-2 (Table 3), however with negative coefficient values, demonstrating that the largest the correction accomplished during treatment, the smallest will be the posttreatment PAR index, and the largest will be the relapse during the postretention period. However, there was a positive correlation between posttreatment and postretention PAR scores (PAR T2 x PAR T3), indicating that the best finished cases presented best occlusions also at the postretention stage, though presenting more PAR index relapse. These results corroborate the study of Nett and Huang ${ }^{29}$ (2005), that evaluated 100 cases randomly chosen by the PAR index and the objective grading system (OGS) and concluded that settling occurs after orthodontic treatment, and the attainment of perfect occlusal results does not ensure stability.

Besides this above cited study, few other studies described the relationship between posttreatment scores and long-term changes ${ }^{12,21,40}$. Kashner ${ }^{21}$ (1999) found that a group of patients treated to a higher level of quality also showed a higher quality result in the long-term. However, other studies found no correlation between treatment quality results and long-term stability ${ }^{12,40}$. The results of the present study might support these prior works, because even though well-finished patients tended to worsen and poorly finished tended to improve ${ }^{29}$, the well-finished patients still had better absolute occlusal relationships at postretention, showed by the result of correlation coefficient for PAR T2 x PAR T3 (positive correlation) (Table 3). The lack of correlation of the study by Woods, Lee and Crawford ${ }^{40}$ (2000) can be explained partly for the wide range of malocclusions appraised, including different treatment plans and protocols ${ }^{40}$, while in the present study the malocclusion type and the treatment protocol were the same in all cases evaluated. 
The Little irregularity index was not correlated to the PAR index at any of the times of evaluation (Table 3), in other words, the mandibular anterior crowding relapse presents a different behavior from the other occlusal characteristics. This result corroborates the assertion that the characteristic more prone to relapse is certainly the crowding of mandibular incisors ${ }^{4,14,27,28}$. The Little irregularity index was significantly correlated for pretreatment and posttreatment with the postretention phase (Table 3).

One might have expected to find that the higher the standard of occlusal finishing at the end of active treatment, the smaller will be the postretention occlusal change. No such relationship was uncovered in this study, however. It can seem senseless, because high standard of occlusal finish was sometimes previously associated to greatest stability in the long-term ${ }^{5,36}$. Even though, on the other hand, intending that cases treated to a normal occlusion result request larger correction during treatment, and it was demonstrated that the larger the correction, the larger the relapse, the correct interpretation of results becomes easier. The consistent information that untreated cases present a relative stability of occlusion cannot be neglected ${ }^{1,3,38}$. Except for the mandibular anterior crowding, the longitudinal changes of untreated patients are minimum and irrelevant ${ }^{1,3,38}$. These mentioned untreated cases can present normal occlusion ${ }^{38}$ or malocclusion ${ }^{1,3}$.

\section{FINAL CONSIDERATIONS}

In the current climate of high quality, accountable and professional healthcare, the demand for orthodontists to provide treatments that are evidence-based is heightening ${ }^{18,23}$. Critical evaluation of the available evidence is needed in Orthodontics. The exact detail regarding longterm occlusal change is incomplete. It is known that untreated individuals undergo longitudinal occlusal change $\mathrm{e}^{1,3,38}$. Similarly, patients treated with orthodontic appliances undergo posttreatment change. Most studies report beneficial occlusal change from treatment ${ }^{13,23}$, followed by some deterioration in the quality of occlusion at the postretention phase $\mathrm{e}^{4,7,28,29,40}$.

Whilst most papers acknowledge the unpredictability of posttreatment change both in regard to its likelihood in an individual and to its extent ${ }^{4}$, it would seem that a high quality of treatment occlusal results relates to a great longterm stability ${ }^{5,27,28,36}$, but by these study results, according to the sample and methodology used, it was proved not to be the reality. An ideal occlusal finish is not synonym of stability ${ }^{12,29,40}$.

Even though an ideal occlusal treatment result does not assure stability, it does not justify to despise the quality and the full detail of final occlusion, because an excellent finish provides best occlusal, functional and mainly esthetic results, besides of oral and masticatory system health including teeth, bone and periodontium ${ }^{11}$.

\section{CONCLUSION}

The quality of orthodontic treatment outcomes is not related to the long-term occlusal stability.

\section{REFERENCES}

1- Afsharpanah A, Feghali R, Hans MG, Nelson S. Assessment of orthodontically untreated adolescents using the PAR index. J Dent Res. 1996;75:363.

2- Al Yami EA, Kuijpers-Jagtman AM, van’t Hof MA. Occlusal outcome of orthodontic treatment. Angle Orthod. 1998;68(5):43944.

3- Al Yami EA, Kuijpers-Jagtman AM, van’t Hof MA. Assessment of biological changes in a nonorthodontic sample using the PAR index. Am J Orthod Dentofacial Orthop. 1998;114(2):224-8.

4- Al Yami EA, Kuijpers-Jagtman AM, van’t Hof MA. Stability of orthodontic treatment outcome: follow-up until 10 years postretention. Am J Orthod Dentofacial Orthop. 1999;115(3):3004 .

5- Andrews LF. The six keys to normal occlusion. Am J Orthod. 1972;62(3):296-309.

6. Barros SEC. Evaluation of efficiency of the Class II treatment without extraction and with extraction of two maxillary premolars. Bauru; 2004. [Dissertation - Master - Bauru Dental School USP].

7- Birkeland K, Furevik J, Boe OE, Wisth PJ. Evaluation of treatment and posttreatment changes by the PAR Index. Eur J Orthod. 1997;19(3):279-88.

8- Boley JC, Mark JA, Sachdeva RC, Buschang PH. Long-term stability of Class I premolar extraction treatment. Am J Orthod Dentofacial Orthop. 2003;124(3):277-87.

9- Casko JS, Vaden JL, Kokich VG, Damone J, James RD, Cangialosi $\mathrm{TJ}$, et al. Objective grading system for dental casts and panoramic radiographs. American Board of Orthodontics. Am J Orthod Dentofacial Orthop. 1998;114(5):589-99.

10- DeGuzman L, Bahiraei D, Vig KW, Vig PS, Weyant RJ, O’Brien K. The validation of the Peer Assessment Rating index for malocclusion severity and treatment difficulty. Am J Orthod Dentofacial Orthop. 1995;107(2):172-6.

11- Dyken RA, Sadowsky PL, Hurst D. Orthodontic outcomes assessment using the peer assessment rating index. Angle Orthod. 2001;71(3):164-9.

12- Fernandes A. The effect of quality of treatment on long-term stability. Los Angeles; 2000. [Thesis M.S. - University of Southern California].

13- Fox NA. The first 100 cases: a personal audit of orthodontic treatment assessed by the PAR (peer assessment rating) index. $\mathrm{Br}$ Dent J. 1993;174(8):290-7.

14- Freitas KMS, de Freitas MR, Henriques JF, Pinzan A, Janson G. Postretention relapse of mandibular anterior crowding in patients treated without mandibular premolar extraction. Am J Orthod Dentofacial Orthop. 2004;125(4):480-7.

15- Gardner RA, Harris EF, Vaden JL. Postorthodontic dental changes: a longitudinal study. Am J Orthod Dentofacial Orthop. 1998;114(5):581-6. 
16- Grainger RM. Orthodontic treatment priority index. Washington, D.C.: U.S. Government Printing Office; 1967.

17- Han UK, Vig KW, Weintraub JA, Vig PS, Kowalski CJ. Consistency of orthodontic treatment decisions relative to diagnostic records. Am J Orthod Dentofacial Orthop. 1991;100(3):212-9.

18- Harrison JE. Evidence-based orthodontics: where do I find the evidence? J Orthod. 2000;27(1):71-8.

19- Holman JK, Hans MG, Nelson S, Powers MP. An assessment of extraction versus nonextraction orthodontic treatment using the peer assessment rating (PAR) index. Angle Orthod. 1998;68(6):52734.

20- Janson G, Brambilla AC, Henriques JF, de Freitas MR, Neves LS. Class II treatment success rate in 2- and 4- premolar extraction protocols. Am J Orthod Dentofacial Orthop. 2004;125(4):472-9.

21- Kashner JE. Does higher quality of treatment translate into a higher quality long-term result? Seattle; 1999. [Dissertation - Master - University of Washington].

22- Keeling SD, Riolo ML, Martin RE, Ten Have TR. A multivariate approach to analyzing the relation between occlusion and craniofacial morphology. Am J Orthod Dentofacial Orthop. 1989;95(4):297305

23- Linklater RA, Fox NA. The long-term benefits of orthodontic treatment. Br Dent J. 2002;192(10):583-7.

24- Little RM. The irregularity index: a quantitative score of mandibular anterior alignment. Am J Orthod. 1975;68(5):554-63.

25- Little RM, Wallen TR, Riedel RA. Stability and relapse of mandibular anterior alignment - first premolar extraction cases treated by traditional edgewise orthodontics. Am J Orthod. 1981;80(4):34965.

26- Little RM, Riedel RA, Årtun J. An evaluation of changes in mandibular anterior alignment from 10 to 20 years postretention. Am J Orthod Dentofacial Orthop. 1988;93(5):423-8.

27- Little RM. Stability and relapse of dental arch alignment. Br J Orthod. 1990;17(3):235-41.

28- Little RM. Stability and relapse of mandibular anterior alignment: University of Washington studies. Semin Orthod. 1999;5(3):191204.

29- Nett BC, Huang GJ. Long-term posttreatment changes measured by the American Board of Orthodontics objective grading system. Am J Orthod Dentofacial Orthop. 2005;127(4):444-50.

30- O’Brien KD, Robbins R, Vig KW, Vig PS, Shnorhokian H, Weyant R. The effectiveness of Class II, division 1 treatment. Am J Orthod Dentofacial Orthop. 1995;107(3):329-34.

31- Otuyemi OD, Jones SP. Long-term evaluation of treated class II division 1 malocclusions utilizing the PAR index. Br J Orthod. 1995;22(2):171-8.

32- Richmond S, Shaw WC, O’Brien KD, Buchanan IB, Jones R, Stephens CD et al. The development of the PAR Index (Peer Assessment Rating): reliability and validity. Eur J Orthod. 1992;14(2):125-39.

33- Richmond S, Shaw WC, Roberts CT, Andrews M. The PAR Index (Peer Assessment Rating): methods to determine outcome of orthodontic treatment in terms of improvement and standards. Eur J Orthod. 1992;14(3):180-7.
34- Richmond S. Personal audit in orthodontics. Br J Orthod. 1993;20(2):135-44.

35- Richmond S, Andrews M. Orthodontic treatment standards in Norway. Eur J Orthod. 1993;15(1):7-15.

36- Roth RH. Functional occlusion for the Orthodontist. Part III. J Clin Orthod. 1981;15(3):174-91.

37- Shah AA. Postretention changes in mandibular crowding: a review of the literature. Am J Orthod Dentofacial Orthop. 2003;124(3):298308.

38- Sinclair PM, Little RM. Maturation of untreated normal occlusions. Am J Orthod. 1983;83(2):114-23.

39- Vaden JL, Harris EF, Gardner RL. Relapse revisited. Am J Orthod Dentofacial Orthop. 1997;111(5):543-53.

40- Woods M, Lee D, Crawford E. Finishing occlusion, degree of stability and the PAR index. Aust Orthod J. 2000;16(1):9-15. 